\section{An Alùress}

on

\section{ABORTION : ITS FREQUENCY AND IMPOR'TANCE."}

\author{
BECKWITH WHITEHOUSE, M.S.JoND., F.R.C.S., \\ PROFESSOR OF MIDWIFERY AND DISEASES OF WOMEN, \\ UNIVERSITY OF BIRMINGIIAM.
}

The subject of this address has been chesen for two reasons-namely, its frequency, and its importance to the indiridual and the community. The increasing number of abortions amongst most white races during the past thirty years has naturally focused attention upon a problem which has always to some extent cxorcised the minds of the medical and legal professions. With a stationary $\mathrm{cr}$ falling birth rate the position naturally becomes more acute, and the prerention of abortion is to-day a responsibility which involves not only the welfare of the individual but also that of the family and the State. A nation with a diminishing birth rate and a high abortion ratio must sooner or later suffer. There appears to be little doubt that, for the present, the day of the large family las gone, for good or for evil. We are told that it is for good, but sometimes I have $\mathrm{my}$ doubts on this matter. I know many large families, families of as many as ten oi a dozen, and $I$ say unhesitatingly that in my experience they are the happiest, and are getting the best out of life. I have spoken to the mother's of these families, mother's from all grades of society, and never once have I heard any expression of regret, either from a social, economic, or physical standpoint.

In this age of mcchanical transport, whoalthy excitement, entertainment, and " rush," the modern cult for limitation of the family by the wholesale promulgation and practice of contraceptive measures is speeding apace. There are too many intentionally sterile marriages to-kay, and perhaps, what is equally as bad, there are too many one-child families growing up. Abortion must therefore be regarded as something more than a trivial accident. Its frequency in some countries to-day is appalling. Gellhorn states that in Germany, in 1890, one abortion occurred to erery ten births. In 1911 the proportion had dropped to one in fire, and in 1919, in Hamburg, the figure had reached one in two. In 1926 two abortion occurred for erery thres births. In earch vear in Germany the actual number of alortions raries between 500,000 and 875,000. In Sorict Russia the artificial termination of pregnancy during the carly months is actually legali\%ed, and State "abortoriums" have been established.

In this country abortion at prescit is not notifiable, and consequently reliable statisties are not arailable. Wren if rotification were established it is doubtful whether the information obtained would be of real value. The attitule of the lay mind to the whole question of aloortion raries tremendously: Nothing is more conveniently forgotten than the termination of an unwanted pregnancy. On the other hand, where such a pregnancy is desired, abortion is a disaster, and its recurrence a real tragedy. Between these two extremes are the number of "so-called" "slight abortions," (asually remembered by some individuals, and as casually related, during the taking of a clinical historr. These are the items which probably would be orerlooked in any system of notification and which would falsify the records.

From such figures as are arailable in the case sheets of hospital records it is a satisfaction to find that in this country we are not at present faced with anything approaching the state of affairs which obtains in certain European areas to-day. Recently I analysed the incidence of abortion among 3,000 of $\mathrm{my}$ hospital and private patients, and found that the ratio of abortions to births was 1:4.7. In a total of 11,430 pregnancies the percentage of abortions was 17.2; and among the total 3,000

* Read before the Oxford Division of the British Medical Association at the Radcliffe Infirmary, Oxford, on October 23rd, 1929. cascs the percentage of women who har aborted at some time or other during their sexual life was 35.3 . For purposes of comparison the cases were grouped into "pre-war" and "post-war" years, and it was interesting and pleasing to find that the proportion was almont the same. In the wise of 1,208 pre-war patients the abortions among 6,021 pregnancies registered $17.7 \mathrm{per}$ cent., and the ratio to births at term was 1:4.6. Among 1,148 post-war cases the percentage of abortion was 16.9 , and the ratio of abortion to births $1: 4.8$. These figures are based upoin information provided by women attending a gynaecological clinic for many different lesions, and of course are open to the criticism previously adranced that they under- rather than orer-estimate the true position of affairs. In the case of the "private" group, it is known that they include certain abortions " procured" for various indications, and therefore they do not give any guide to the incidence of " natural" as opposed to "intcntional " abortion

The criminal practice of the artificial termination of pregnancy naturally vitiates the value of any series of figures which purport to ascertain the frequency and causation of natural abortion. We know that many procured abortions occur in the community, but it is a very difficult, in fact practically an impossible, task to obtain direct information upon the artual number. There are many cases of this nature where neither the services of a doctor nor those of a midwife are asked, and if no complication arises the event is probably soon forgotten. The chief offender's in this group are those married women in whom pregnancy is not desired or for whom it is inconvenient. During the last few years I have been approached by many more married than single women with the object, expressed or implied, of terminating a pregnancy. The reasons put forward are various: sometimes, but very rarely, it is on the ground of economy; more frequently because the previous confinement had been complicated or difficult and there was an honest fear to approach the risks of labour again.

Another group includes those women who become pregnant again late in life, when the other members of the family are growing up. More than one patient of thi group has felt her position acutels, and has told me that she "could not go through the disgrace of having anothar child." These actual words demonstrate the peculiar attitude of mind of some individuals in dealing with what, after all, is a purely physiological function.

One fact has been impressed upon me time after time. and that is the pertinacity of the married woman who set out with a determination to terminate her own pregnancs. Argument is useless, and when she has failed to produce the required result by means of a popular purgative pill or a prescription from a fashionable chemist " to remedy all female menstrual irregularities," she approaches her own doctor. If he finds no indication to interfere she goes to somebody else, and erentually possibly does find some individual who is able to satisfy his own conscience that a modical reason exists for the evacuation of the uterine contents. If help (annot be obtained in this derious manuer there is always the homely knitting-necdle, crochet-hook, douche nozyle, or the professional criminal abortionist. Women in this statio will not listen to words of adrice oi warning. They are optimists of the first water, individuals who do not care what happens as long as it does not happen to themselves. I do not propose to say anything more on this question of criminal abortion. The subject has bess discussed very fully recently by the Medico-Legal Society, the Society of Medical Officers of Health, and the Roval Society of Medicine, and I refer you to the Transactions of these societies for an expression of the considered and current riews of those best qualified to speak.

A much more intriguing subject to the obstetrician, as distinct from the medico-legal expert, is the cause of natural abortion. Why is it that some women abort time after time and others never do so in spite of the application of those factors which are commonly regarded as provocative agents? When pregnancy is desired the occurrence of abortion is a great disappointment to a woman, and shonld the accident be repented it is indeed regarded as a clisaster. Most of us are familiar with cascs of this type, and we know from experience how difficult it is in the 
al)sence of definite pathological physical signs to adrise our patients for the future. It is this aspect of abortion that I wish to consider more particularly to-day.

\section{Syphilis and thortion.}

In the first place let me say a few words npon the relation of syphilis to abortion and premature birth. I think it may be said that syphilis is commonly regarded at heing a cause of repeated miscarriage. For some years I have been a little doubtful about the truth of this is -wertion, and in order to obtain more definite information (n) the matter I approached Dr. Assinder, the officer in (harge of the Government Venercal Department at the General Hospital, Birmingham. He very kindly instituted an inquiry for me upon 678 patients who had attended his rlinic. The most important group conccrus tertiary rrphilis, for it is obvious that in the case of primary and acondary srphilis the disease had nothing to do with the abortions, the records having been made when the patient first presented herself. The miscarriages and stillbirths had lappened in the past.

In the cine of 493 tertiary srphilities the perentage of abortions was 37.3, almost identical, in fact,' with the figure of 35.3 which is the percentage of abortions from will causes. It cannot be said, therefore, that srphilis increases the predisposition to abort during the early months of pregnancy. If, howerer, the stillbirths are included, a further addition of 22.1 per cent. must be mate, giving the high total of 59.4 per cent. In the case of 28 congenital syphilities no abortions or miscarriages had occurred. These figures, therefore, tend to confirm my original view that syphilis is not so much a cause of abortion during the early months of pregnancy as of prenature labotr or stillbirth. It is after placentation is (ompleted that the syphilitic virus exerts its chinf effect, and produces those macroscopic and microscopic changes in the foetus, its umbilical cord and membranes, with which pathologists are familiar.

The Titality of the Germ rells.

Ibortion of the products of gestation from the pregnant uterus is by no means a phenomeron confined to the human species. It happens in many domestic animals, and a study of the causes which lead to its occurrence in these lower types may throw light upon some of the obscure atar's in hinman pathology.

Professor Arthur Robinson, working with ferrets, foumd that the germ cells of certain perfectly normal healthy animals are incompatible with the corresponding gern cells of other healthy animals of the opposite sex. The result is usually alssilute sterility. In certain cases, how"rer, there is evidence of death in the uterus of fertilized wa, which Robinson thinks may be due to this factor of incompatibility. Gestations in the ferret are usually uultiple, and each pregnancy has a corresponding corpus luteum in the ovary. By a series of sections of the ovaries and uteri it is possible to correlate the corpora lutea and the pregnancies, and Professor Rohingson has found that, in the same healthy animal, whilst some fertilized ora or \%ygotes develop in a normal manner, others from the same oestrus sometimes die and are absorbed. This occur's in the absence of any local lesion in the uterus, and therefore he attributes the death to incompatibility of the ormm and spermatozoon, or what nay be termed a lack of inherent vitality of the germ cells. Abortion due to this cause may he regarded as caused by sexual inefficiency of either the male or fenale, or both.

Whether such incompatibility of certain or all of the sexual cells occurs in the human species it is difficult to sar. There is no doubt that many women who have heen sterile for some years abort once, twice, or eren more times if, and when, pregnancy occirs. In an analysis of 1,233 patients, giving the relation of abortion to parity, 1 found that in a total of 336 chillless women 265 were absolutely sterile and 71 aborted after they had becomo pregnant. Three had had four successive abortions, any two as many as five. Incompatibility may be the canse of these disasters, but proof can only be olitained when evidence is brought of the fertility of each indiridual with another partner
Can defective vitality of the germ cells be acquired? This again is a question where it is impossible to be clogmatic about the answer. There is, however, some evidence indicating that the problem of abortion is sometimes assiated with factors of heredity. The place of an individuat in the family is certainly a point to be considered. Screral cases of repeated and unexplained abortion have come under my notice where it has transpired that the pationt is the last member of an exceptionally large family -a cortraceptive experiment on the part of Nature. One such rase I quote, as it appears to afford an excellent illustration of exhausted reproductive capacity.

Mrs. L., aged 33, married and stcrile for five rears, was delivered of a dead macerated child at the seventh month of her first gestation, no cause being assigned. The Wassermann reaction was negative. She is an undersized individual, weighing 7 st., and is herself a $7 \frac{1}{2}$ months child, the last of a family of thirteen. Her immediate brothers and sisters were all premature. Two wero stillborn, one has a congenital cardiac lesion, and another tuberculosis. A point of great interest is that Mrs. L.'s own mother was also a premature child and the last of a family of sixteen.

As parity increases there is a progressive increase in the incidence of the number of women who abort. Failure of reproductive power may be a factor, but before this can be proved information must be fortheoming of the place of abortion in the list of pregnancies of exceptionally fertile women. It is, of course, a difficult matter upon which to obtain unequivocal data, for all kinds of extrancols influences are introduced as the number of pregnancies increases. I think, therefore, that more reliable facts can be collected, when available, by careful investigation of the family history, and especially of the place in the family of a given individual.

\section{The Relation of the Decidua to Abortion.}

The derelopment and function of the uterine decidua call for special consideration in relation to abortion. The decidua is, of course, the highly dereloped endometrium peculiarly adapted for the reception and implantation of the fertilized orum or zygote. It is now gencraily accopted that this thick fleshy structure which fincs the pregnani uterus is but the fully dercloped phase of growth which is initiated immediately after carch menstrual period, or menstrual abortion, as $T$ prefer to call it. This progressive development is stimulated and maintained hy a hormone elaborated first in the ciraafian follicle and then in the corpus luteum when the oüryts has left the former. If this hormone is withdrawn by destruction, excision, or even aspiration of the (iraatian follicle or the corpus luteum, the decidua necrows. If the decidua is that of the unimpregnated uteru, then an artificial menstrual "period" is produced. On tho other hand, if a fertilized orum is embedded in the dreidua, abortion naturally follows. This faet, originally demonstrated by Fränkel in Vienna, has since been eonfirmed by many observers.

Teal and Parkes have lately shown that lutcin dreclonment is controlled by the anterior lobe of the pituitary gland. In rats it is possible by the administration of extracts of this gland to sensitize and stimulit! the derelopment of the endometrium to an extreme degree of decichual formation during the resting sexual phase. The production of these artificial placentomata depends npon abnormal luteinization of the oraries by the pitnitary extract. It is evident, then, that the normal development and function of the decidual organ are very complex phenomena, intimately associated with the phrsiology of the ovary and pituitary gland. These organs, and especially the ovary, assume, therefore, consideralls importance in their relationship 'sth to normal prengnancy and the causation of abortion.

There are many organic pathological comclitions asonciated with premature death and expulsion of the uterine contents where lesions in the ovary may be contributing factors. In the case of nterine fibroids, and in retrorersion of the uterus with prolapse of the oraries, lioth Graafian follicles and corpora lutea frequently show path:logical lesions. Hacmorrhage and Graafian and lutein haematomata are common, as well as the so-called theralutein cysts. Both uterine fibroids and retroversion ale 
associated on occasion with abortion, and it is conccivable that the deciding factor which kills the ovum and leads to the abortion is the lutein lesion which so often ccexists. Cystic states of the corpus luteum have long been known to occur in relation with ectopic gestation and with re.icular mole, and I have had two opportunities of examining the ovaries in the case of carneous moles, where the same lesion was present.

It is, of course, possible that the ovarian lesions may be the result and not the cause of the leath of an orum. There is no information arailable as yet to show what happens to a corpus luteum when pregnancy is suddenly terminated at different stages of its derelopment. Does it atrophy, degenerate, or become crstic? These are points which should be investigated, owing to the possibility of abortion producing a permanent lesion in the ovary.

Great strides have been made during the last few years with regard to ovarian and uterine physiology. New chapters have been written, and light has been thrown upon problems which were formerly obscure. There is still, however, much for us to learn. Take the matter of innerration of the ovaries and uterus. Why is it that mental or physical shock is sometimes followed by abortion? The decidua itself is not supplied by nerve elements, but the ovaries are very liberally supplied with both ganglia and nerve fibres. Sections of ovarian tissne stained by Bielschowsky's method show a highly complex system of nervo elements in relation to the Grafian follicles and capillary blood ressels in their immediate proximity. Abortion rarely follows immediately upon a nervoas stimulus, but occurs usually a few days later, when presumably necrosis of the decidua has taken place. Does this mean that the corpus luteum has been inhibited in its function through the network of nerve plexuses and ganglia which surround it?

Turning to the endometrium itself, there is little doubt that its integrity and power to respond to sensitization by the lutein hormone are essential factors for the normal implantation and development of the zygote. If it is hypertrophic, as in the case of uteri the seat of fibromyomata or chronic subinvolution, or has been injured by repeated attacks of chronic inflammation, it responds to the lutein stimulus in a defective manner, with the result that the zygote develops in an abnormal environment. Curettings from uteri which have recently aborted frequently show an atrophic or poorly developed decidua, or a decidua which is infiltrated with inflammatory cells. It is reasonable to suppose that the physiological function of such a decidual organ is defectire and that the interchange of food factors through the chorio-decidual space is also abnormal.

In the case of 300 women who gare a clinical history of three or more abortions, uterine lesions were present in 53.3 per cent.; and evidence of chronic inflammation in the pelvis, in relation with either the genital tract or pelvic peritoneum, occurred in 26.6 per cent. of the patients.

The Relation of Pathological Ora to Abortion. Certain embryologists, notably $\mathrm{H}$ is and more recently Mall, have drawn attention to the interesting fact that a rery large proportion of human ora that are aborted are abnormal in some respects. The largest number of abortions occur during the second and third months of gestation, and Mall has stated that 50 per cent. of the ova that he has examined during this period are pathological. Many and varied are the types of abnormality that occur. In some the embryo consists merely of a nodule representing the umbilical vesicle. The amnion may or may not be present. Sometimes the chorion only exists. In others the embryo is destroyed after the development of the amnion and may be represented only by the stump of the umbilical cord. Spina bifida is common, as also is anencephalus. These pathological embryos, if they survive, produce monsters, and it is perhaps a satisfactory provision of Nature that the factors which cause the abnormality usually exert such a radical influence that the lesions are incompatible with further development. The ovum dies, becomes a foreign body, and as such is expelled by the uterus As so large a proportion of abortions consist of pathological ora, the question has been raised by Mall as to whether it is justifiable to attempt to prolong a pregnancy when abortion is threatened before placentation of the or um is complete. I cannot subscribe whole-heartedly to this view, as, of course, one knows of many early threatened abortions which have subsequently progressed normally and terminated with the birth of a normal and healthy child. At the same time, I can recall two instances when abortion was averted with considerable care, only to result in the birth later of children with spina bifida and anencephalus respectively.

My irterest in the investigation of the uterine products of abortion was stimulated by association with the late Professor Peter Thomson, whose views coincidcd largely with those of Mall. The great majority of early abortions that fall into our hands are damaged by trauma and are useless for scientific investigation owing to rupture of the foetal membranes. With care, however, it is possible in the course of time to collect a certain amount of useful material, and such inrestigations as $I$ have been able to make tend to confirm Mall's views on the high incidence of pa hological ora among the products of abortion.

In these aborted ova lesions are not by any means confined to the embryo itself. Disease of the chorion frequently coexists. The most constant and the earliest evidence of a pathological state is the presence between the chorionic villi of a mueoid substance containing leucocytes. The syncytium grow's into this mass in an irregular manner, and in some cases actually invades the mesoderm of the villi. The villi themselves vary considerably in their numbers and distribution. In some ova they are very scanty; in others they are irregularly scattered over the surface of the gestation sac; and in yet others they exhibit various signs of degeneration, as shown by mucoid, hyaline, or fibrous change.

Are these abnormal ova that are so commonly aborted the result of external influences, such as a diseased or abnormally functioning decidua, or are they caused by inherent pathological attributes in the germ cells? There is a diversity of opinion on this matter among embryologists, but the weight of evidence, I think, is in support of Mall, who considers that pathological forms are causerl by external influences and not by anatomical or physiological defects in the orum or spermatozoon. As he points out, one most important argument in support of the influence of environment is the fact that when the ovum is implanted in an abnormal position where the decidua is absent or defective-for example, the Fallopian tube96 per cent. of the embryos are abnormal. This fact alone serves to emphasize the importance of a healthy and functioning decidua in the well-being of the dereloping ovum.

Another, and equally important, argument is that every trpe of abnormal embryo and monster known to occur in the human species can be produced in other organisms by artificial means from normal ova and embryos. Spina bifida can be produced in tadpoles by subjecting frog spawn to the action of common salt, a 0.7 per cent. solution giving 100 per cent. of this abnormality. Magnesium solutions have been used by Stockard to produce cyclopia in certain fishes, with 50 per cent. success. When sea-urchins' eggs are submitted to the action of lithium salts inversion of the blastoderm occurs, giving rise to nodular atrophic embryos, such as are found in human aborted ova. Calcium salts, in certain concentrations, according to Loeb, retard the growth of the blood vessels of the developing embryo, and indirectly affect its general development. All kinds of gross abnormalities-for example, anencephalus, double monsters, etc.-have been produced by experimerital teratologists by nechanical trauma applied to developing embryos at different stages of development. There is abundant proof, therefore, that an abnormal physical or biochemical environment can, and does, act in a deleterious manner upon the developing ovum. At the same time, as pointed out by Professor Arthur Robinson in a recent discussion on the causes of sterility and abortion at the Royal Society of Medicine, pathological ova can develop in the absence of any obvious macroscopic or microscopic lesion in the uterus of animals. Spina bificla is the commonest anomaly, and this has occurred independently of any demonstrable pathological lesion in 
the case of Robinson's cxperimental work on tho ferret. Ho concludes, therefore, that inherent abnormal physiological attributes in the gene are responsible for the pathological lesions that are encountered. In the presence of such divergent views, the truth probably lies somewhere between the two, and both factors may on different occasions be concerned in the phenomena which I have discussed.

Abortion in Relation to Nutrition of the Ovum.

From the preceding remarks it is evident that impairment of nutrition, resultirg from faulty implantation, abnormal decidual develophirent, absence of essential food factors, or the existence of lethal toxins, is a potent factor in the etiology of early abortion.

The maintenance of an adequate source of food materials is not affected by the same mechanisin in all members of the mammalian family. In certain ungulates and a few rodents the secretion of the uterine glands is the main source. from which the developing embryo derives its nourishment. This secretion, known as " uterine milk," is an albuminous fluid containing cast-off cellular elements, but very little is known beyond this. Its exact chemical composition has, I believe, hitherto not been ascertained. In the human subject the zygote is dependent upon absorption from the maternal blood, except for a short period of its existence when the syncytium is actively burrowing and embedding itself in the decidua. At this stage even in the human ovum some of the uterine glands are opener up by the trophoblast, and blood is effused into their lumina pari passa with the destruction and solution of the decidual strona cells. The secretion of the uterine glands is normally rich in calcium and iodine, as shown by chemical analysis of the menstrual discharge; and in the developed decidua, both of menstruation and of pregnancy, there is a marked retention of secretion in the largo dilated glands of the stratum spongiosum. I cannot think that this active retention of secretion is of negative value, or is purely atavistic. It may be that there is some diffusion of secretion between the glands and stroma cells of the decidua. Aratomy and comparative embryology have demonstrated the minute structure of the ovum and process of embedding, but there is still much to learn with regard to the physiology of that remarkable organ, the decidua.

Among stock-raisers and veterinary surgeons much importance is attached to-day to matters of feeding and the influence of various food factors upon sterility, and the number and weight of the progeny. At a recent discussion on abortion at the Royal Society of Medicine I drew attention to this matter, particularly with relation to the value of iodine. Experiments at the Staffordshire Farm Institute have shown that sows receiving iodine farrowed 50 per cent. more young than sows that had no iodine. At the Royal Experimental Station, Budapest, when iodine was given to pregnant sows, the average weight of the farrows at weaning was nearly 50 per cent. over that of the group that received no iodine. In the case of birds, the Rowett Institute and West of Scotland Agricultural College found that the egg yield in pullets which received iodine went up 50 per cent. in one year over a pen that had no iodine in the diet. The r.rgregate egg production where iodine was given in the form of potassium iodide was nearly double that of a pein where iodine was withheld. There is no doubt, therefore, of the value of this element to the pregnant animal, and I cannot help thinking that the iodine content of the uterine secretion in the human female has a similar sionificance. We know that certain inorganic toxic agents- for example, lead-are transmitted to the ovum, and that they act deleteriously upon the development and function of the syncytium. It is quite possible, therefore, that other agents, especially calcium and iodine, are similarly transmitted, and that they act in a beneficial manrer.

During the last few years a considerable amount of work has been done in connexion with the essrntial food factors known as vitamins, and in 1922 Evans and Scott publisherl the first of a series of papers upon the "existence of a hitherto unknown dietary factor essential for reproduction." This substance, known as the anti-sterility vitamin fat-soluble "E," has been extcnsively investigated by Evans and his co-workers, and the results of the research are published in an elaborate monograph. Evans worked exclusively with rats, and found that, although fertilizaticn and implantation of the ovum occurs in the absence of vitamin $\mathbf{E}$, the cmbryos begin to die about the eiglit' day of gestation, and are later absorbed. They shcw general under-development, especially in the mesoblastic tissues, entodermal villi, blood islands, and allantois.

The data given in Evans and Burr's monograph proviclcs very interesting reading, and if their results are confirmest a new and fertile field of investigation is opened up into the causes of some obscure carly abortions in the liuman subject. One important fact which emerges from the work is that if vitamin $\mathbf{E}$ is withheld from the diet of an aninal the initial available stock of this factor is gradually exhausted, both for the general bodily economy and also by any intercurrent pregnancies. Such an animal, althou'h fertile at first, will later abort owing to an " $\mathbf{E}$ " deficiency. Subsequently it can be cured of what may be termed the "sterility disease" by the substitution of an "E" for an "E"-free ration.

The distribution of vitamin $\mathbf{E}$ in nature is chiefly concentrated in certain seeds and leaves, especially wheatgorm, lettuces, peas, alfalfa, bryophyllum, and begonia. 'To a less extent it is found in the yolk of eggs, but traces only are present in animal muscle. The vitamin is apparently not destroyed by drying and desiccation at a temperature of $100^{\circ} \mathrm{C}$, , an important practical point in the preparation of vegetable products-for example, lettuco and wheat-germ-for therapeutic purposes. The value of wheat is due exclusively to the storing of vitamin $E$ in the germ, as white flour is powerless to produce a cure in animals rendered sterile by feeding on " $\mathbf{E}$ "-free rations. Chemically the vitamin has not hitherto been actually isolated, although fractional distillation has produced an active body similar in constitution and physical propertics to vitamin $\mathbf{A}$ and cholesterol. A remarkable resemblance in certain chemical reactions exists between this antisterility vitamin and one of the ovarian hormones. As Evans points out, " the partial destruction during vacuum distillation at $2000^{\circ} \mathrm{C}$, the total destruction by acetyl chloride and bromine, the stability to hydrogenation in the presence of platinum black, the molecular weight, and the elementary analysis all show a general similarity of the ovarian hormone to vitamin E."

This brings mo back to the all-important relationship which exists between the ovary and the developing ovum. I have alrcady explained the influence the lutcin hormone excrts over the growth of the decidua. Dees the similarity in composition and chemical properties between the hormone and vitamin $\mathbf{E}$ imply a similar physiological influence over the devcloping embryo? In other words, dces the ovary not only provide the ovum, but also the essential growth factor upon which the future development of the ombryo depends? This conception of an essential "growth factor" being present in the ovarian hormone provides an interesting field for thought and investigation, not only in relation to abortion, but also in connexion with certain neoplasms. It appears possible, indeed, that the presence of an ovarian "growth hormone" may account for the rapidity of growth and size of some ovarian tumours, both benign and malignant.

The work of Evans upon "vitamin E" of course necls confirmation by other investigators in other laboratorics. Also, it has still to be shown by clinical observation whether the conclusions based upon experiments on rats are applicable to the human specics.

During the past few years opportunities have naturally occurred of testing what may be termed the " new sexual physiology " in its application to the treatment of recurrent abortion in the human subject. It is impossible, of coursc, in isolated instances to know whether a given result is post and not propter treatment, but the following two cases certainly appeared to have benefited from the exhibition of ante-natal therapy on the lines discussed.

Casc 1.-Mrs. L., aged 40, married for three years. Her first pregnancy terminated at the seventh month with the stillbirth of twins. The next gestation aborted at the twelfth week. The third pregnancy again ended with the birth of a macerated foctus at about the twenty-eighth week. The Wassermann reaction 
in the case of both husband and wife was negative, and no obvious cause could be found to account for the obstetric clinical history. In March, 1926, the patient again became pregnant, and she was immediately placed upon a diet rich in vitamin $\mathbf{E}$, together with calcium lactate (60 grains per diem) and a preparation of ovarian hormons. The pregnancy progressed to term in a normal manner, and a elild weighing $10 \frac{1}{2} \mathrm{lb}$. was delivered by Caesarean section on Decombei 22nd, 1927 .

C'ase 2.-Mrs. S., aged 32, a 2-para. Her first child was premature, and weighed $6 \frac{1}{2} \mathrm{lb}$. It was reared with difficulty. The sccond pregnancy was complicated by hydramnios, and a child showing an extreme degree of spina bifida was born at the thirty-second week of gestation. The patient became pregnant again at the end of November, 1928. She was placed upon a similar regime, with the addition of iodine, and a healthy child weighing $8 \mathrm{lb}$. was born in September, 1969. The existence of a small elongated dimple over the lower part of the lumbar spine and sacrum showed the tendency to spina bifida which had complicated the preceding gestation.

\section{Contagious Abortion.}

I will conclude with a short reference to the question of contagious abortion in relation to the human species. In veterinary medicine infection of the uterus with Bang's bacillus is well known, and it is a frequent cause of abortion among certain infected herds. The Ministry of Agriculture has issued several leaflets upon the subject, and the importance of the infection is emphasized among all farmers and stock-raisers. Recently attention has been drawn to the possibility of transmission of Bang's bacillus to the human pregnant female, and a few undoubted cases of this infection have occurred both in this country and in Denmark.

As a cause of abortion in the human species, however, infection of this nature is sporadic and rare. I have only met with one undoubted example, and this occurred some years ago in the wife of a farmer who had infected stock upon his land. The case was at first regarded as an ordinary infected abortion, but the continuance of pyrexia and the persistence of a grey muco-purulent discharge led to a bacteriological investigation of the uterine cavity. An unusual bacillus in pure culture was found in the discharge, and this coincided in appearance and cultural characteristics with a control tube of Bang's bacillus, supplied by Messrs. Evans and Co. of Liverpool. Following this case a bacteriological investigation was instituted in other cases of infected abortions. Altogether 50 cases were examined, but no other example of infection with Bang's bacillus was found.

The infection is undoubtedly rare, but the possibility of the disease should be remembered, especially in the cast of what appear to be septic abortions in rural areas.

The figures accompanying this paper were obtained for me by Miss King, the sister in charge of $\mathrm{my}$ department, and by $\mathrm{Mr}$. Jeafferson, my registrar, to whom I take this opportunity of acknowledging my indebtedness.

\section{MASTOID DISEASE WITHOUT OTORRIIOEA. BY \\ E. WATSON-Williams, M.C., Сн.M., F.R.C.S.ED.,}

SURGEON IN CHARGE OF THE EAR, NOSE, AND THROAT DEPARTMENT, BRISTOL ROYAL INFIRMARY.

Acvte suppurative middle-ear disease is sometimes classified as "mild" in which resolution occurs without perforation of the drum, or "severe" with perforation and aural discharge. With both forms there is no doubt mastoiditis in some degree-suppuration in the antrum and air cells, and associated reaction in the surrounding bone. But only a small proportion of cases go on to what is clinically recognized as "mastoid disease"; in the majority, and almost invariably in the "mild" type, resolution occurs.

Yet if we adopt this classification it is important to bear in mind that definite and eren extensive mastoid disease can on occasion occur where there is not, and has never been, any aural discharge. On examining the records of some 300 mastoid operations performed personally since the beginning of 1925 , I find fifteen such cases occurring in fourteen patients. ${ }^{1}$ Such a ratio is probably much above the normal, as two recent groups of cases are included in this period. With the possible exception of No. 12, these cases, notes of which are subjoined, may be regarded as primary acute otitis-that is, ncither recurrent nor chronic. In each case the occurrence of any previous ear trouble, and especially any discharge, recent or remote; has been the subject of particular inquiry.

Preceding Illness.--Influenza had preceded the ear trouble in both the adults $(9,14)$ and that or a " cold" in three more cases $(8,10,13)$. Scarlet fever had been the precursor in one (1). But no fewer than eight of the fourteen patients had been in apparently perfect health immediately before the onset of otitis $(2,3,4,5,6,7,11$, 12). No. 12 was a congenital syphilitic, but there had been for years no evidence of the disease. Probably in Case 6 the otitis was a sequel of the incomplete adenoid operation.

Pain was present in every case at some point, but in sereral it was intermittent $\left(11_{R}, 11_{L}, 14\right)$, or insufficient for some days to cause. the patient to scek advice $(2,3$, $4,10)$.
Tenderness over the mastoid antrum or process is, except pain, probably the most constant sign of mastoiditis. But in five cases it was quite inconspicuous $(1,5,8,11 \mathrm{R}, 11 \mathrm{~L})$, and was absent in two (4, 14 early).

Fever was absent in one case throughout, and in both the adults at the beginning. Only four of the patients had a temperature above $100^{\circ} \mathrm{F}$. when first seen.

The tympanic membrane was examined in every case by means of an illuminated magnifying speculum. It was noted as being quite normal in appearance in eight of the fifteen ears $\left(1,2,3,5,10,11_{L}, 12,13\right)$.

Post-aural Oedenia.-A word in passing as to this symptom. It is in so many cases the outward and visible sign of mastoiditis, and is so invariably illustrated as such in textbooks, that there appears to be some risk lest it should be regarded as a diagnostic criterion, without which we can exclude this complication. ${ }^{1}$ It was, in fact, the occurrence of swelling that in ten of these fifteen cases decided me to operate on the mastoid forthwith. Nevertheless, it is well to emphasize that even in acute primary otitis, disease of the mastoid, perhaps quite extensive, may occur where post-aural swelling is inconspicuous (7), or entirely absent $\left(4,8,9,11_{\mathrm{R}}, 1_{\mathrm{L}}, 14\right.$ early).

Pathology.

The ages of the patients in years were $1,2,3,5,6,7,8$, $8,10,11,13,16,26,34$. These ages are what one would expect in a group of primary acute otitis. A striking feature of the records (which are usually very brief) is the frequency with which mention is made of the cellular nature of the bone. This conspicuous derelopment of the cells may be an etiological factor-that is, it was because the bone was unusually cellular that mastoid swelling appeared early and before perforation. But since this feature was specially noted in four of the five cases where no oedema had occurred, that camnot be the only explanation.

In four cases a perisinus abscess was discovered at operation $(4,7,8,14)$, and in two of these the sinus contained old clot breaking down $(4,8)$. It is to be noted that in both these cases the drum had appeared normal when first examined, mastoid oedema was absent, and tenderness absent in one and quite slight in the other.

The pus was examined in eight cases, in two of which no growth of organisms was obtained. During 1929 special attention was directed to the possibility of a streptococcus mucosus infection. Both then and before the report was uniformly "streptococcus," that particular type not being found. Furtliermore, the clinical course was not that 